\title{
The Impact Characteristics of Fabric Reinforced Hybrid Composites
}

\author{
MARINA BUNEA*, RADU BOSOANCA, CRISTIAN ENI, NICOLETA CRISTACHE, VICTORITA STEFANESCU \\ Dunarea de J os University of Galati, 47 Domneascã Str., 800008, Galati, Romania
}

\begin{abstract}
In this research, the impact behavior of hybrid composite materials subjected to low-velocity impact using the drop-weight installation was investigated. For this study were manufactured eight hybrid materials. All the materials were tested to 90) impact energy. The effect of fabric types used in outer layers on impact performance was studied. The impact characteristics of hybrid materials with G1 glass fabric sheets were compared with those of hybrid materials with G2 glass fabric sheets. The damage surfaces of hybrid laminates were examined by visual investigation. The results obtained showed that the using of G2 glass fabric in structure of hybrid materials improved considerable the impact characteristics.
\end{abstract}

Keywords: hybrid composites, woven fabric, low-velocity impact, epoxy matrix

Tend to get the materials with high strength, lightweight and low cost contributed to the development of a wide and varied range of reinforced composite materials, which can be used in all domains. Generally, like reinforcement are used plain simple woven fabrics because present the same properties in both directions of fibers[1], which has a great importance for impact characteristics [2]. Often are used carbon fabrics due to its rigidity in aerospace industry, glass fabrics due to its mechanical strength in transport industry and aramid fabrics impact strength and high energy absorption capability in military applications.

The carbon fiber reinforced epoxy composites exhibit the similar or better mechanical properties in comparison with metals [3]. Because of its rigidity, the carbon fabrics have a low impact resistance, but it can be improved by using of other types of fabrics with high impact strength to the formation of composites. By hybridizing of composites it can be obtained the materials with desired properties, allowing to control of impact parameters. Using the highmodulus fibres can be improved the damage tolerance to low-impact velocity and increased the delamination resistance due to bending stiffness mismatch [4]. The hybrid composites can be a useful solution to many industrial applications by taking advantage of good properties of both carbon and glass fibers [5] or carbon and aramid fibers [6-9].

Randjbaran and co-authors [10] have determined that the impact characteristics of hybrid laminates depend significantly on the fabrics of outer layers. So, the laminates with outer layers made of glass fabric absorb less energy than those made of aramid fabric. It is not recommended to use the carbon fabric for these layers, but is better to use a combination of carbon fabric and glass fabric for medial layers.

Sayer et al. [11] have studied the impact response of two types of hybrid laminates (glass-carbon/epoxy) and results showed that the perforation threshold of CG hybrid composite is approximately $30 \%$ higher than that of the GC hybrid composite, but by increasing from 4 carbon layers to 8 layers, perforation threshold changed from approximately 69.5 J to 72.4 J. Also, Sevkat et al. [12] determined that the hybrid laminates with glass plain fabric outer sheets and graphite fabric sheets core exhibit better impact resistance than those with graphite fabric outer sheets and glass fabric sheets core.

When the composite materials are exposed to low velocity impact, its damage surface depends on shape of impactor [13-16] and in the case of cylindrical impactors with hemispherical head, the puncture force and energy varies with impactor radius [17]. The energy absorption capacity of composites is very important for its modes of failures, because energy is absorbed by material through elastic, plastic deformation and through creation of new surfaces through failure [18]. The impact damage is important for in service damage composites, because it can reduce the compressive residual strength up to $60 \%$ $[19,20]$.

In this study was examined the response of hybrid materials subjected to drop-weight impact tests at 90 J energy and was analyzed the effect of fabric types of outer layers and the effect of glass fabric density on impact characteristics.

\section{Experimental part}

Materials and methods

For this research were manufactured eight types of hybrid laminates with epoxy matrix by hand lay-up method, whose architectures are given in table 1 . For the reinforcement of laminates were used simple plain woven fabrics, where $\mathrm{C}$ denotes carbon fabric, $\mathrm{K}$ denotes aramid fabric, G1 denotes glass fabric with $163 \mathrm{~g} / \mathrm{m}^{2}$ specific density and $\mathrm{G} 2$ denotes glass fabric with $390 \mathrm{~g} / \mathrm{m}^{2}$ specific density. The epoxy resin used was EPIPHEN RE 4020 and hardener EPIPHEN DE 4020, with the mixing ratio for resinto-hardener in weight was 10:3. First four hybrid laminates have the same architecture like other four hybrid laminates differing by glass type fabric.

All the laminates contain 17 layers, where for the medial layer was used a special fabric denoted by M (table 1). For obtaining this fabric was used a mixed fabric made of carbon fibers and aramid fibers in geometry $2 \times 1$ warp direction (two carbon fibers alternating with one aramid fiber) and $1 \times 2$ fill direction, where each second aramid fiber was replaced by a glass fiber together with a $0.2 \mathrm{~mm}$ diameter wire of tin covered cooper. The cross-section microscopic images of hybrid laminates are ilustrated in figures $1,2$.

All the drop-weight impact tests were performed to University of Minho, Guimaraes. For determining the impact characteristics of hybrid composites was used CEAST Fractovis Plus 9350 impact testing machine, which consists of a drop tower equipped with an $20 \mathrm{~mm}$ diameter impactor with hemispherical head, a variable crosshead weight arrangement and a load transducer with $22.24 \mathrm{kN}$ 


\begin{tabular}{|c|c|c|}
\hline Material & Layer configuration & Thickness \\
\hline $\mathrm{N} 11 \mathrm{H}$ & {$\left[0_{3 \mathrm{C}} / 0_{3 \mathrm{~K}} / 0_{2 \mathrm{G}_{1}} / \overline{90_{\mathrm{M}}}\right]_{\mathrm{S}}$} & 4.566 \\
\hline $\mathrm{N} 12 \mathrm{H}$ & {$\left[0_{3 \mathrm{~K}} / 0_{3 \mathrm{G} 1} / 0_{2 \mathrm{C}} / 90_{\mathrm{M}}\right]_{\mathrm{S}}$} & 4.166 \\
\hline $\mathrm{N} 13 \mathrm{H}$ & {$\left[0_{3 G 1} / 0_{3 C} / 0_{2 K} / 90_{M}\right]_{s}$} & 4.310 \\
\hline $\mathrm{N} 14 \mathrm{H}$ & {$\left[0_{3 G 1} / 0_{3 \mathrm{~K}} / 0_{2} \mathrm{c} / 90_{\mathrm{M}}\right]_{S}$} & 4.350 \\
\hline $\mathrm{N} 21 \mathrm{H}^{-}$ & {$\left[0_{3} \mathrm{C} / 0_{3 \mathrm{~K}} / 0_{2 \mathrm{G}} / 90_{\mathrm{M}}\right]_{\mathrm{S}}$} & 4.897 \\
\hline $\mathrm{N} 22 \mathrm{H}$ & {$\left[0_{3 \mathrm{~K}} / 0_{3 \mathrm{G}} / 0_{2 \mathrm{C}} / 90_{\mathrm{M}}\right]_{\mathrm{S}}$} & 4.666 \\
\hline $\mathrm{N} 23 \mathrm{H}$ & {$\left[0_{3 G_{2}} / 0_{3} \mathrm{C} / 0_{2 \mathrm{~K}} / 90_{\mathrm{M}}\right]_{\mathrm{S}}$} & 4.684 \\
\hline $\mathrm{N} 24 \mathrm{H}$ & {$\left[0_{3 \mathrm{G} 2} / 0_{3 \mathrm{~K}} / 0_{2 \mathrm{C}} / 90_{\mathrm{M}}\right.$} & 4.628 \\
\hline
\end{tabular}

Table 1

THE ARCHITECTURE OF FORMED MATERIALS

Carbon fabric: $4 \times 4$ plain weave, $160 \mathrm{~g} / \mathrm{m}^{2}, 260 \mu$ m thickness.

Aramid fabric: $6.7 \times 6.7$ plain weave, $173 \mathrm{~g} / \mathrm{m}^{2}, 280 \mu \mathrm{m}$ thickness.

Glass fabric G1: $12 \times 12$ plain weave, $163 \mathrm{~g} / \mathrm{m}^{2}, 180 \mu \mathrm{m}$ thickness

Glass fabric G2: $6 \times 6$ plain weave, $390 \mathrm{~g} / \mathrm{m}^{2}, 190 \mu \mathrm{m}$ thickness.
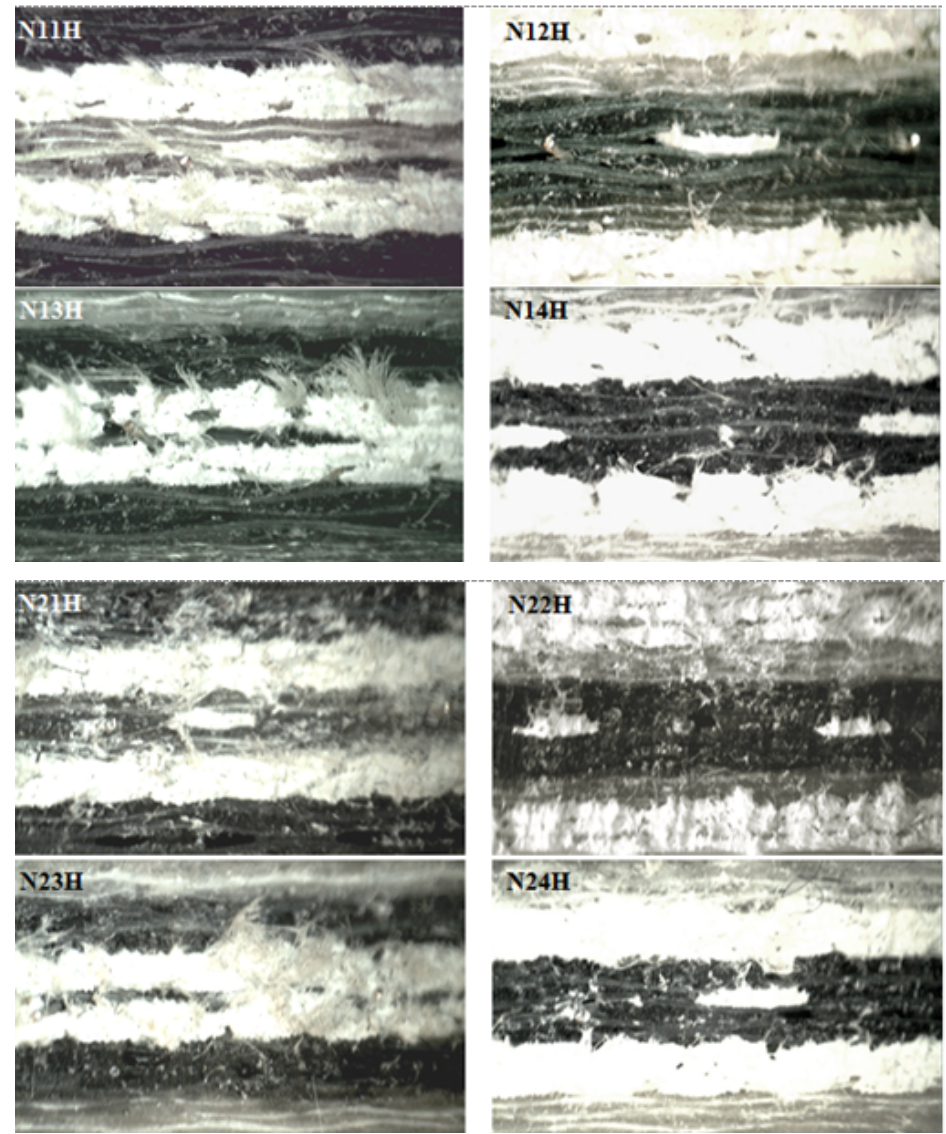

Fig. 1. The cross-section microscopic images of lower specific density glass fabric reinforced hybrid laminates capacity mounted into impactor, which send data during impact test to data acquisition system. For data acquisition and evaluation was used software program VisuallMPACT (fig. 3).

All drop-weight impact tests were performed at constant $920 \mathrm{~mm}$ height, $4.248 \mathrm{~m} / \mathrm{s}$ velocity, 90.629] energy and $10.044 \mathrm{~kg}$ total mass. The specimens size was
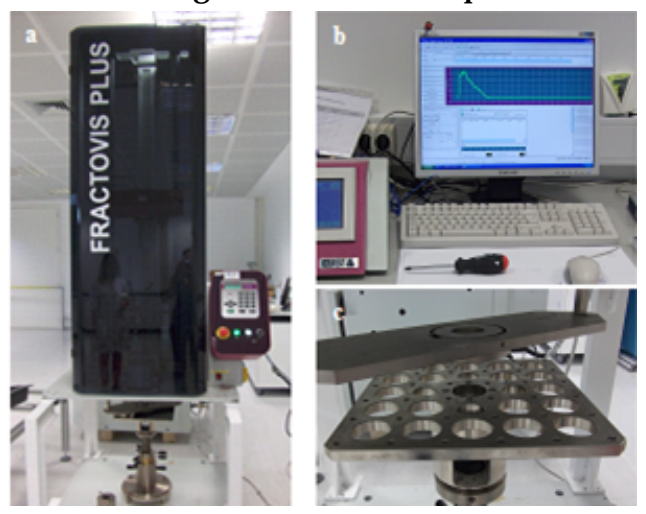

Fig. 3. The drop-weight impact system: a -CEAST Fractovis Plus 9350 machine, $b$ - data acquisition system and c - clamping system
$190 \times 190 \mathrm{~mm}$ and it were tested in four points. All tests were performed according of standard EN ISO 6603 [21, 22]. In bottom side of impact machine is a clamping system for fixture of specimens with $40 \mathrm{~mm}$ interior diameter and $2 \mathrm{~N}$ clamping force.

\section{Results and discussions}

According standard EN ISO 6603-2:2000, key impact parameters collected by data acquisition system are maximum load, energy at maximum load, deflection at maximum load and puncture load, which is a half of maximum load, energy at puncture load, deflection at puncture load. These parameters are shown by the loaddeflection, load-time and energy-time curves, by means of which it can be understood the impact behavior of composite materials subjected to drop-weight impact loading.

Generally, the load-deflection curves show rebounding, penetration and perforation situations, where the rebounding of impactor from plate surface at the impact contact is described by closed curves and the open curves describe the penetration and perforation of the specimens 


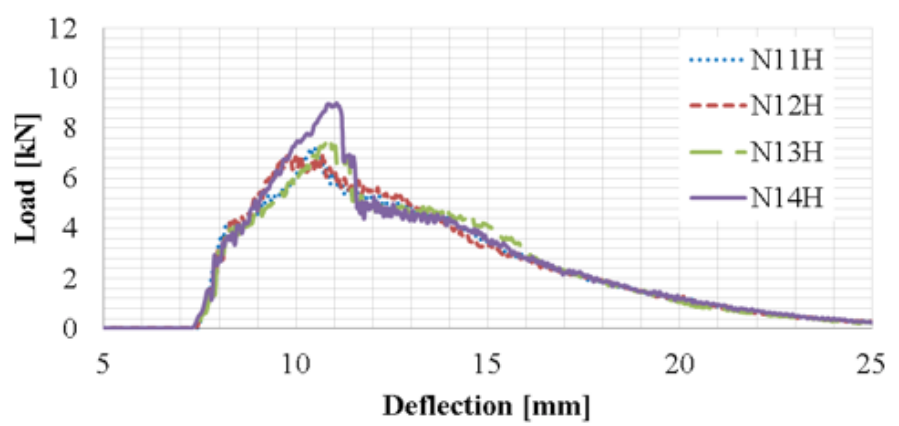

Fig. 4. The load - deflection curves for the lower specific density glass fabric reinforced hybrid laminates subjected to 90J impact energy

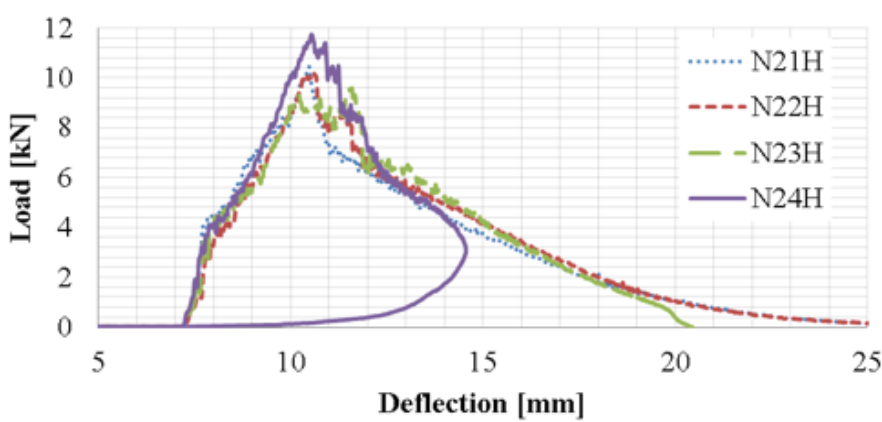

Fig. 5. The load - deflection curves for the higher specific density glass fabric reinforced hybrid laminates subjected to 90) impact energy

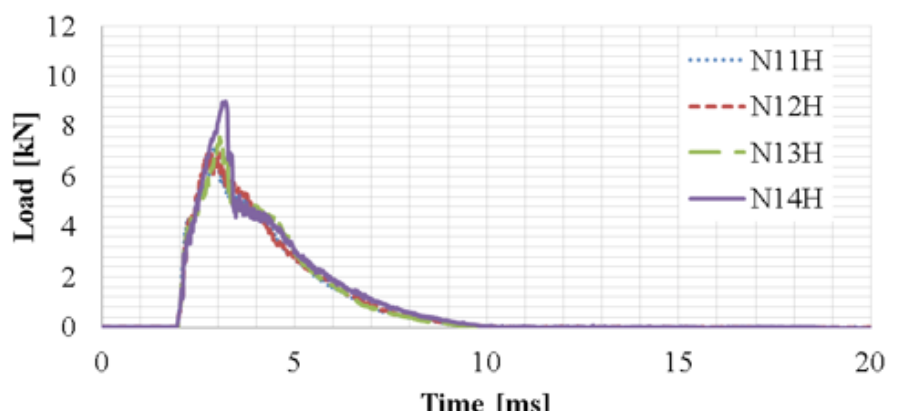

Fig. 6. The load - time curves for the lower specific density glass fabric reinforced hybrid laminates subjected to 90] impact energy

by impactor [11]. Due to curves data it can be determined maximum and permanent deflection, contact time, absorbed and excessive energy [23].

In figures 4 and 5 are plotted the load - deflection curves for hybrid laminates subjected to 90] impactenergy, which represent three situations: rebounding, penetration and perforation. So, N24H hybrid laminate was non-perforated, $\mathrm{N} 23 \mathrm{H}$ hybrid laminate was totally penetrated and other hybrid materials were perforated. Analyzing the figures 6 12 , it can be observed that the hybrid materials which contain G2 glass fabric layers exhibit a higher impact performance than hybrid materials which contain $\mathrm{G} 1$ glass fabric layers, so as hybrid materials with G2 glass fabric layers show higher maximum load and impact energy than others. So, G2 glass fabric reinforced hybrid composites demonstrate higher impact resistance than G1 glass fabric reinforced hybrid composites due to higher specific density of G2 glass fabric, being approximately double in comparison with specific density of G1 glass fabric. About contact time, it can be observed hybrid materials with G2 glass fabric layers exhibited longer impact contact time than hybrid materials with G1 glass fabric layers and nonperforated $\mathrm{N} 23 \mathrm{H}$ and $\mathrm{N} 24 \mathrm{H}$ hybrid composites exhibited the longest impact contact time.

Generally, keeping the same architecture of the hybrid composite materials and replacing the lower specific density glass fabric with one whose specific density is

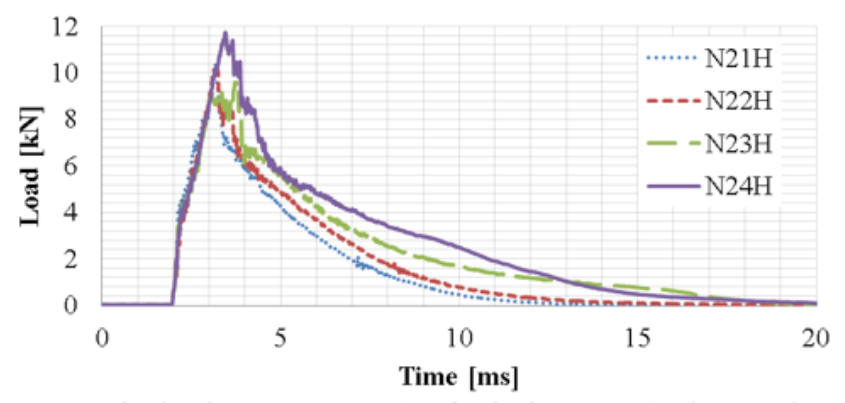

Fig. 7. The load - time curves for the higher specific density glass fabric reinforced hybrid laminates subjected to 90] impact energy

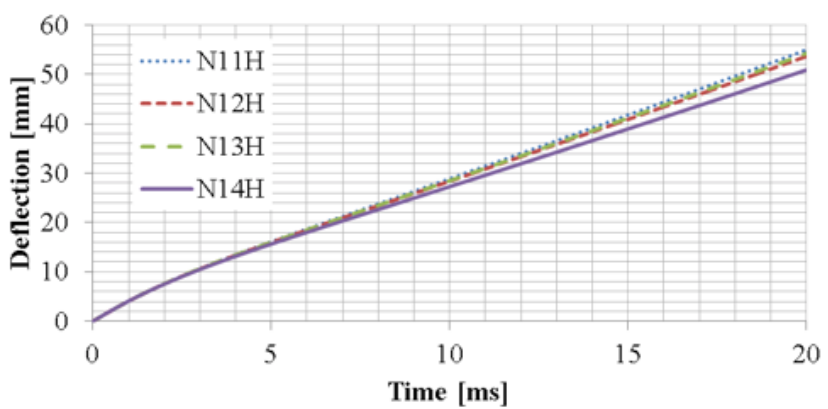

Fig. 8. The deflection - time curves for the lower specific density glass fabric reinforced hybrid laminates subjected to 90 impact energy

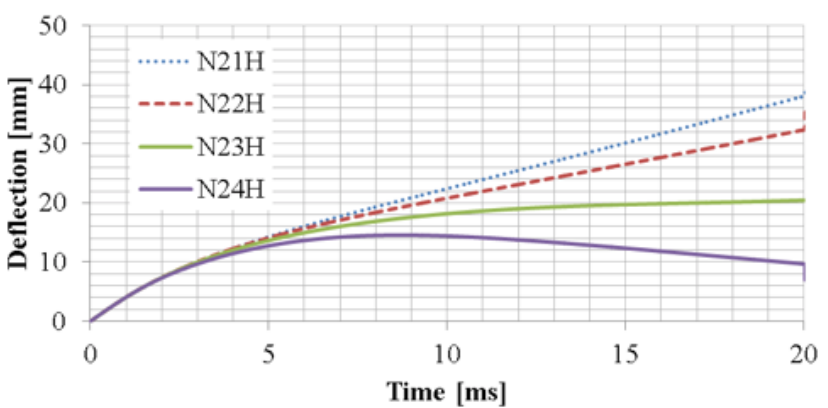

Fig. 9. The deflection - time curves for the higher specific density glass fabric reinforced hybrid laminates subjected to 90J impact

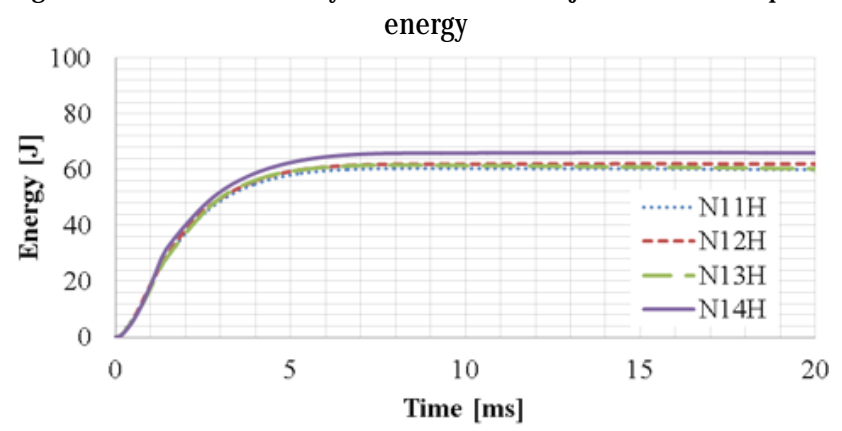

Fig. 10. The energy - time curves for the lower specific density glass fabric reinforced hybrid laminates subjected to 90 J impact energy

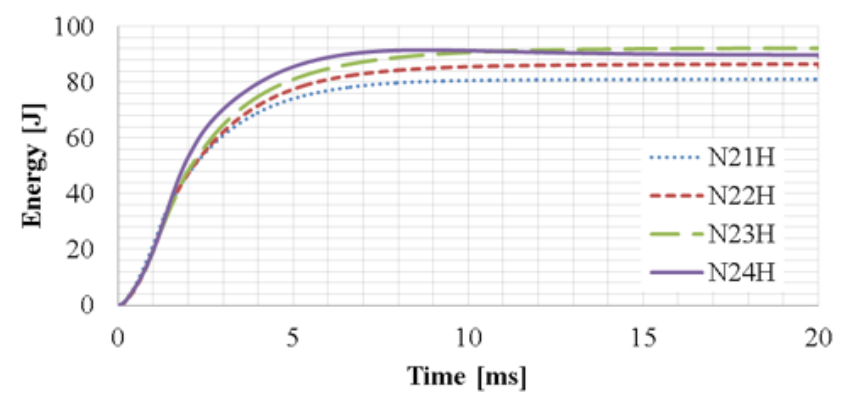

Fig. 11. The energy - time curves for the higher specific density glass fabric reinforced hybrid laminates subjected to 90] impact energy 


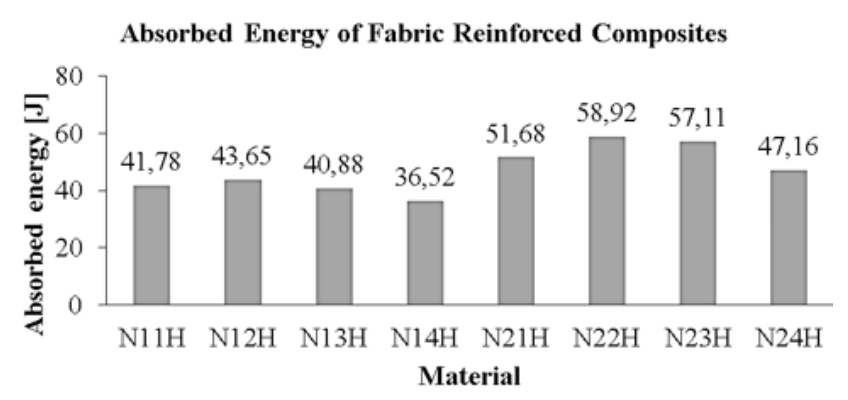

Fig. 12. The absorbed energy of all hybrid laminates subjected to 90] impact energy
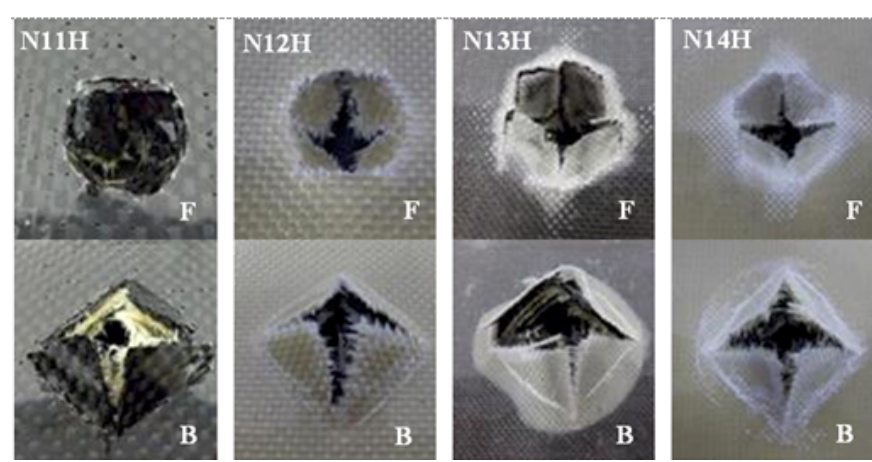

Fig. 13.The images of impact damage surfaces of the specimens subjected to $90 \mathrm{~J}$ energy impact tests (impacted surfaces - $\mathrm{F}$ and non-impacted surfaces - B
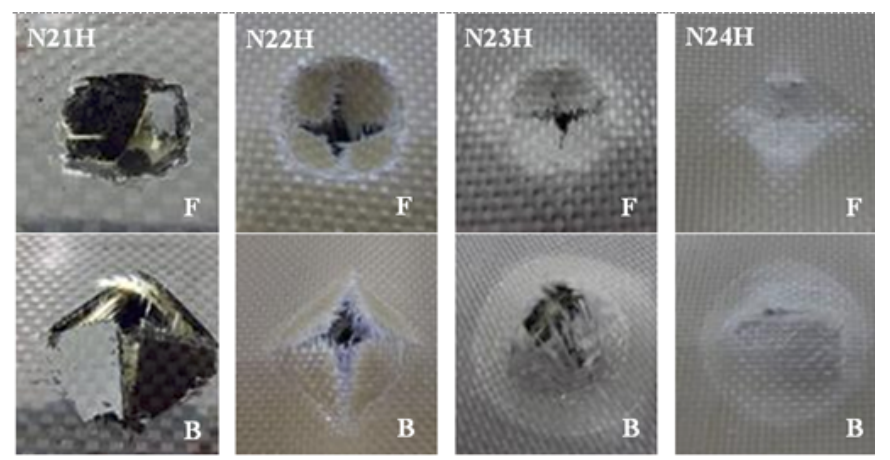

Fig. 14.The images of impact damage surfaces of the specimens subjected to 90 J energy impact tests (impacted surfaces - F and non-impacted surfaces - $B$

higher, it could be improved the impact characteristics of the materials.

The hybrid composite material $\mathrm{N} 24 \mathrm{H}$ shows a higher impact performance than $\mathrm{N} 23 \mathrm{H}$ hybrid composite material, because its outer three layers are made of $\mathrm{G} 2$ glass fabric sheets preceded by three aramid fabric sheets and medial layers are made of carbon fabric sheets, but the outer three layers made of $\mathrm{G} 2$ glass fabric sheets of $\mathrm{N} 23 \mathrm{H}$ hybrid composite material are preceded by three carbon fabric sheets and medial layers are made of aramid fabric sheets. The hybrid materials with outer layers made of carbon fabric sheets exhibit the lowest impact characteristics due to the rigidity of this fabric type. When the impact resistance of the materials increases, the impact energy increases, too. So, impact energy of hybrid materials with G2 glass fabric layers is higher than impact energy of hybrid materials with $\mathrm{Gl}$ glass fabric layers necessary for their failure (figs. 10, 11).

The increasing of impact energy leads to increasing of impact maximum load, deflection and contact time between impactor and specimen.

By examining of energy - time curves, it can be determinate the absorbed energy and excessive energy. Absorbed energy is calculated by difference between total energy and energy at peak load and excessive energy is

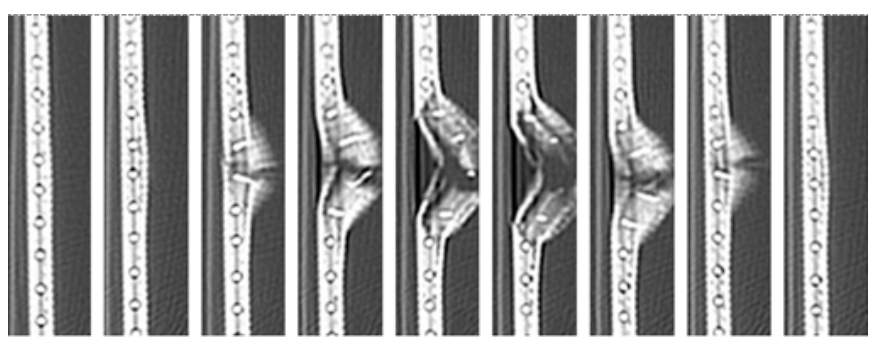

Fig. 15. The performed tomographic images at every $5 \mathrm{~mm}$ of damaged area section of $\mathrm{N} 23 \mathrm{H}$ hybrid composite material subjected to 90) energy impact.

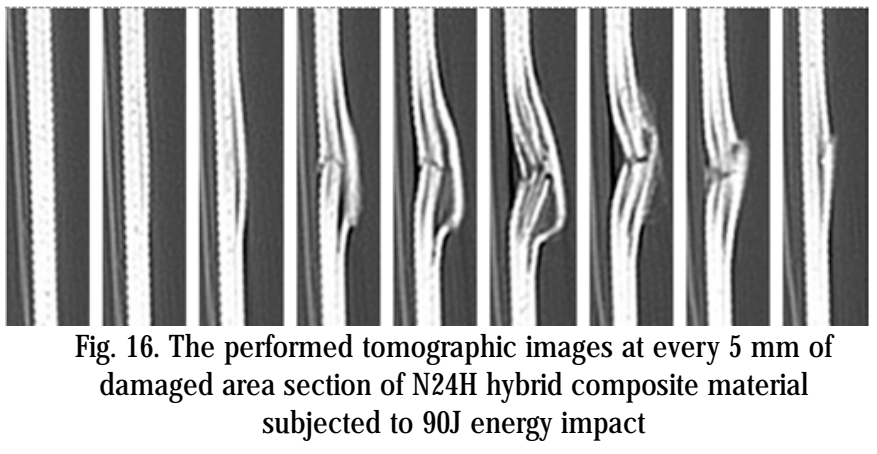

calculated by difference between energy at maximum load and absorbed energy. The excessive energy is the energy retained by impactor for rebound it from specimen surface at the impact contact, because the specimens cannot absorb whole impact energy.

In figure 12 are plotted the absorbed energy values by hybrid composite materials subjected to drop-weight impact tests at 90] energy. The hybrid composite materials with G2 glass fabric layers exhibit higher ability to absorb impactenergy than other hybrid composite materials. The hybrid composites $\mathrm{N} 12 \mathrm{H}$ and $\mathrm{N} 22 \mathrm{H}$ absorbed more energy in comparison with other hybrid composites of their group, due to the outer layers made of aramid fabric sheets.

Using the glass fabric sheets in outer layers the energy absorption capacity is reduced, which leads to increasing of excessive energy. In figures 13 and 14 are illustrated the images of impact damages on impacted and nonimpacted sides of hybrid laminates subjected to 90] impact energy. Analyzing the images, it can be observed easy that all hybrid plates were perforated, excepting N24H hybrid laminate. In figures 15 and 16 are showed the tomographic images at every $5 \mathrm{~mm}$ of damaged area section of $\mathrm{N23H}$ and $\mathrm{N} 24 \mathrm{H}$ hybrid composite materials subjected to $90 \mathrm{~J}$ energy impact, because other hybrid epoxy laminated of this study were perforated.

It can be seen that the dominant failure modes of the studied hybrid materials are matrix cracks and breakage, fibers breakage and fibers pull out and the back faces were split along the fill and warp directions. The failure modes of fabric reinforced composites, generally, depends on fiber-matrix bond quality, on mechanical properties of used fabric types in structure of material, on arrangement of fabric reinforced layers types and angle fiber orientation. So, it is important that the outer layers made of hybrid materials to be made from fabrics with highest impact resistance.

\section{Conclusions}

The response of hybrid composite materials subjected to drop-weight impact at 90] energy was investigated. The impact characteristics of hybrid laminates with Gl glass fabric sheets and those of hybrid laminates with G2 glass fabric sheets were compared. The effect of fabric types used for outer layers on impact performance was studied. The conclusions made under study are the following: 
- all the hybrid laminates were failed at 90 impact energy, excepting hybrid laminate $\mathrm{N} 24 \mathrm{H}$;

- the hybrid laminates with Gl glass fabric sheets exhibit lower impactcharacteristics than those of hybrid laminates with G2 glass fabric sheets. So, the density of the fabrics affects the impact performance of the composite materials;

- the hybrid materials with outer layers made of $\mathrm{G} 2$ glass fabric sheets show a higher impact resistance than the hybrid materials with outer layers made of aramid fabric sheets;

- the impactresistance of $\mathrm{N} 24 \mathrm{H}$ hybrid material is higher than that of N23H hybrid material, because of outer layers made of G2 glass fabric sheets of N24H material preceded by aramid fabric sheets and the medial layers were made of carbon fabric sheets, while in the structure of $\mathrm{N} 23 \mathrm{H}$ material the aramid fabric sheets and carbon fabric sheets were inverse arranged;

- the hybrid materials with outer layers made of aramid fabric sheets show the highest ability to absorb impact energy in comparison with the hybrid materials of their group;

- by visual investigation and tomographic images of damaged surfaces after impact tests, it was observed that the surfaces of the materials with carbon fabric reinforced outer sheets supported more deteriorations than those with glass or aramid fabric reinforced outer sheets;

- thickness did not influenced on impact performance of the studied hybrid composite materials.

\section{References}

1. AKOVALI, G., UYANIK, N., Handbook of Composite Fabrication, Rapra Technology Limited, ISBN 1-58957-263-4, 2001.

2. DEBORAH, D. L. C., Composite Materials: Science and Applications, Second Edition, Elsevier, ISBN 978-1-84882-830-8, 2010.

3. VOICU, R., Structural Characterization and Mechanical Behaviour of Carbon Fiber/epoxy Composite for Aeronautical Field, Materiale Plastice 49, No. 1, pp. 34-40, 2012.

4. DAVID-WEST, O. S., ALEXANDER, N. V., NASH, D. H., BANKS, W. M., Energy absorption and bending stiffness in CFRP laminates: The effect of 45 plies, Thin-Walled Structures 46, pp. 860-869, 2008.

5. HOSSEINZADEH, R., SHOKRIEH, M. M., LESSARD, L., Damage behavior of fiber reinforced composite plates subjected to drop weight impacts, Composites Science and Technology 66, pp. 61-68, 2006.

6. STEFANESCU, V., BUNEA, M., CIRCIUMARU, A., Impact analysis of fabric reinforced plates, Mat. Plast., 52, no. 2, 2015, p. 198

7. BRIA, V., DIMA, D., ANDREI, G., BIRSAN, I.G., CIRCIUMARU, A., Tribological and wear properties of multi-layered materials, Tribology in Industry 33 (3), pp. 104-109, 2011.
8. BIRSAN, I.G., CIRCIUMARU, A., BRIA, V., UNGUREANU, V., Tribological and electrical properties of filled epoxy reinforced composites, Tribology in Industry, 31 (1-2), pp. 33-36, 2009.

9.BUNEA,M., BOSOANCA,I.,BOSOANCA,R.,BODOR, M., CIRCIUMARU, $A$., Bending and compressive properties of fabric reinforced composites, Mat. Plast., 52, no. 3, 2015, p. 368

10. RANDJ BARAN, E., ZAHARI, R., ABDUL JALIL, N. A., ABDUL MAJID, D. L. A., Hybrid Composite Laminates Reinforced with Kevlar/Carbon/ Glass Woven Fabrics for Ballistic Impact Testing, The Scientific World Journal, Volume 2014, Article ID 413753.

11. SAYER, M., BEKTAS, N. B., SAYMAN, O., An experimental investigation on the impact behavior of hybrid composite plates, Composite Structures 92, pp. 1256-1262, 2010.

12.SEVKAT, E., LIAW, B., DELALE, F., RAJU, B. B., Drop-weight impact of plain-woven hybrid glass-graphite/toughened epoxy composites, Composites, Part A, Nr. 40, pp. 1090-1110, 2009.

13. PADAKI, N. V., ALAGIRUSAMY, R., DEOPURA, B. L., SUGUN, B. S., FANGUEIRO, R., Low velocity impact behavior of textile reinforced composites, Indian J ournal of Fibre \& Textile Research, Vol. 33, pp. 189-202, 2008.

14. FAROOQ, U., MYLER, P., Efficient computational modeling of carbon fiber reinforced laminated composite panels subjected to low velocity drop-weight impact, Materials and Design 54, pp. 43-56, 2014. 15. FAROOQ, U., MYLER, P., Ply Level Failure Prediction of Carbon Fiber Reinforced Laminated Composite Panels Subjected to *** Low Velocity Drop-Weight Impact Using Adaptive Meshing Techniques, University of Bolton, UK, 2014.

16. MITREVSKI, T., MARSHALL, I. H., THOMSON, R., The influence of impactor shape on the damage to composite laminates, Composite Structures 76, pp. 116-122, 2006.

7. HILDEBRAND, M., A comparison ofFRP-sandwich penetrating impact test methods, VTT Manufacturing Technology, Technical Research Centre of Finland, ESPOO, 1996.

18. HOSUR, M. V., ADBULLAH, M., JEELANI, S., Studies on the lowvelocity impact response of woven hybrid composites, Composite Structures 67, pp. 253-262, 2005.

19. SANTOS, M. J., SANTOS, J. B., AMARO, A. M., NETO, M. A., Low velocity impact damage evaluation in fiber glass composite plates using PZT sensors, Composites: Part B 55, pp. 269-276, 2013.

20. GUAN, ZH., YANG, CH., Low-Velocity Impact and Damage Process of Composite Laminates, J ournal of Composite Materials, Vol. 36, No. 07, 2002.

21. *** European Standard EN ISO 6603-1: 2000.

22. *** European Standard EN ISO 6603-2: 2000.

23. AKTAS, M., BALCIOGLU, H. E., AKTAS, A., TURKER, E., DENIZ, M. E., Impact and post impact behavior of layer fabric composites, Composite Structures 94, pp. 2809-2818, 2012.

Manuscript received: 15.12 .2016 